\title{
UM MANIFESTO PARA MOÇAMBIQUE: A TERCEIRA VIA DE Ngoenha e Castiano
}

\section{Luca Bussotti ${ }^{1}$}

\begin{abstract}
Resumo: Mergulhado numa profunda crise de valores, com uma classe política altamente corrupta e incapaz de oferecer perspetivas credíveis para o seu futuro, Moçambique viu os filósofos Ngoenha e Castiano abrir um debate inovador, mediante a proposta de um Manifesto ético-político. O Manifesto preconiza uma "terceira via" alternativa à primeira (a socialista, sem liberdades, mas com justiça social), assim como à segunda (a liberal, com liberdades individuais formalmente garantidas, mas sem solidariedade, nem justiça social), de forma a re-fundar o sentido de uma identidade coletiva nacional abalada pela perda de um projeto comum à jovem nação moçambicana. $\mathrm{O}$ artigo aqui apresentado procura, além de compulsar o significado da proposta, dar uma interpretação da mesma, enfatizando os méritos, assim como destacando as limitaçóes, construindo o diálogo entre o Manifesto e a tradição filosófica moçambicana e, no geral, africana. A conclusão é de que o Manifesto representa uma das pouquíssimas contribuições para voltar a pensar Moçambique, a partir da sua "historicidade", nos seus aspetos éticos, políticos e identitários, numa altura de crise generalizada do país.
\end{abstract}

Palavras-chave: Filosofia Moçambicana. Ética. Crise de valores. Historicidade.

\section{INTRODUÇÁO}

Poucos dias antes das eleiçóes gerais de 15 de outubro de 2019, Severino Ngoenha e José Castiano, dois entre os pensadores mais destacados de Moçambique e da inteira África lusófona, primeiro nas redes sociais

\footnotetext{
1 Professor no Programa de Pós-Graduaçáo em Sociologia e Pesquisador no Centro de Estudos Avançados da Universidade Federal de Pernambuco (UFPE), Recife, PE - Brasil. Investigador no Centro de Estudos Internacionais de Lisboa (CEI-ISCTE), Lisboa - Portugal. Docente no curso de Doutorado em Paz, Democracia, Movimentos Sociais e Desenvolvimento Humano da Universidade Técnica de Moçambique (UDM), Maputo - Moçambique. (D) https://orcid.org/ 0000-0002-17203571. E-mail: labronicus@gmail.com.
}

https://doi.org/10.1590/0101-3173.2022.v45esp.06.p89

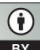


(Facebook), depois em formato de livro publicaram o Manifesto por uma terceira via. Um estranho título, que evoca, por um lado, uma inspiração marxista ou utópica (que os próprios autores desmentem, em várias circunstâncias, ao longo do texto), e, por outro, um keynesismo progressista revisitado, na esteira da terceira via de Anthony Giddens, na altura do governo britânico de Tony Blair (que também os dois autores, de forma explícita, recusam).

O que é, portanto, esse Manifesto e o que é essa Terceira via moçambicana, se as referências fundamentais e intuitivas são desmentidas pelos autores? E por que, na véspera das eleiçôes, eles sentiram a necessidade de publicar um texto tão significativo, o qual, pelo menos na classe dos intelectuais e dos políticos moçambicanos, teve um impacto considerável?

As respostas a tais questóes podem ser de dois tipos: especulativas e analíticas. Às primeiras pertencem as ilaçôes que alguém, nos bastidores moçambicanos, levantou de imediato depois da saída do livro. Elas aludiam à procura de protagonismo político direto, por parte dos dois autores. Graças inclusivamente às conversas tidas com eles, sobretudo com Ngoenha, em Maputo, assim como ao desdobramento dos fatos pós-eleitorais, uma tal hipótese ficou desprovida de qualquer fundamentação. Ademais, a abordagem analítica e hermenêutica ao texto confirma que não houve intenção alguma, por parte dos autores, em se tornarem protagonistas políticos (o que, entretanto, seria legítimo, assim como fez Alberto Ferreira, candidatando-se pela Renamo para o Parlamento, enquanto ainda era Diretor da Faculdade de Filosofia da Universidade Eduardo Mondlane), tão que, no próprio Manifesto, eles desmentem abertamente a intenção de formar um novo grupo ou partido, fora dos já existentes.

Se, portanto, convém seguir uma metodologia analítica, aderente ao conteúdo do texto em questão, o primeiro elemento a ser esclarecido é quais foram os objetivos que levaram esses dois filósofos a elaborar o Manifesto, qual o pano de fundo deste e que tipo de proposta emerge da sua leitura.

Para responder a tais questóes, o artigo desenvolve uma análise subdividida em quatro partes, além da presente Introdução. A primeira faz uma contextualização do cenário político e ético de Moçambique, hoje, que teria induzido os autores a propor o Manifesto, dialogando com as suas obras anteriores e, mais em geral, com o pensamento filosófico moçambicano; a segunda assenta no conceito, central no livro assim como em toda a produção de Severino Ngoenha, de "historicidade", procurando identificar 
as reflexôes histórico-filosóficas dos autores em volta do passado nacional, desde o colonialismo até a luta armada de libertação e à guerra dos 16 anos, por terminar com a análise da Primeira Via (o socialismo) e da Segunda Via (o liberalismo); a terceira procura destacar os elementos propositivos e inovadores do Manifesto junto à sociedade moçambicana e, finalmente, a última faz um escrutínio crítico das possíveis ambiguidades, contradiçóes, mas também contribuiçóes que o livro traz para o debate público, em nível nacional. As conclusôes fazem um balanço do que foi descoberto, mediante o supramencionado escrutínio, propondo novas inquietaçóes de pesquisa filosófica no contexto moçambicano.

\section{As RAZÓES do MANIFESTO: O CONTEXTO ÉTICO-POLÍTICO DE MOÇAMBIQUE CONTEMPORÂNEO}

O motivo que estimulou as reflexóes presentes no Manifesto se resume num termo e num conceito próprio da filosofia marxiana: em Moçambique, hoje, segundo os dois autores, um espetro está pairando, com toda a sua carga negativa. Trata-se do espetro da "desolação" e da "dissolução" (NGOENHA; CASTIANO, 2019, p. 3). O que é que esses conceitos querem significar, nas intenções dos autores?

A explicação é relativamente simples e incide no âmbito ético, antes do que político e econômico. A ideia dos autores é de que a sociedade moçambicana esteja atravessando um momento de grave e repentina perda de valores humanos básicos (que Castiano, em várias obras, tem identificado com o "neoliberalismo" - ver CASTIANO, 2018), tendo "malabarismos, malandrice, roubalheira" ganho um espaço enorme na convivência social (NGOENHA; CASTIANO, 2019, p. 6). Um dos autores, Severino Ngoenha, já tinha proposto uma definição tão eficaz quâo dura da postura ética das classes políticas locais, assim como de boa parte da sociedade moçambicana: a dolarcracia, a qual, no Manifesto, volta a aparecer, como forma "normal" de lidar com o próximo, segundo uma atitude meramente utilitarista e individualista. A dolar-cracia representaria, segundo Ngoenha (2016), o elemento essencial da transição entre regime socialista e regime liberal, assumindo a democracia, pois, uma forma destorcida e completamente negativa.

Seria, portanto, a dólar-cracia o aspeto que mais contribuiu, principalmente entre as classes mais jovens, a valorizar e de certa maneira ressuscitar a imagem de Samora Machel, primeiro presidente de Moçambique, 
em época socialista, que já tinha sido abandonado pela mesma Frelimo, salvo um resgate em grande estilo do presidente Guebuza (no governo entre 2004 e 2014), que mandou edificar estátuas de Machel em todas as cidades do país. Ngoenha introduz esse argumento ético, a partir do livro sobre Samora Machel, transformando-o num ícone e ultrapassando assim as muitas críticas que até hoje são movidas a esse expoente do socialismo africano, devido à sua política de intransigente asperidade contra os opositores e às inúteis violaçôes contra os direitos humanos mais básicos (NGONHA, 2009).

Se o Manifesto representa o culminar do pensamento engajado de Severino Ngoenha (e de José Castiano) (NGOENHA; CASTIANO, 2011), um tal engajamento perdeu, em parte, o otimismo que tinha caraterizado a reflexão filosófica desses dois pensadores. Com efeito, é a partir da formulação do conceito de dólar-cracia, por parte de Ngoenha, e do impacto do neoliberalismo em Moçambique, do lado de Castiano, que o viés crítico que sempre caraterizou o pensamento dos dois filósofos acentuou os traços de pessimismo, para ultrapassar os quais será necessário - como se verá mais adiante - uma dose relevante de voluntarismo.

Quando é que o "otimismo crítico" deixou espaço ao "pessimismo dolarocrático"?

O momento de transição do socialismo para o liberalismo (início da década de 1990) e os primeiros anos de democracia (com as primeiras eleições multipartidárias, as quais se realizaram em 1994) foram assinalados por uma certa veia de "otimismo crítico" por parte do pensamento filosófico moçambicano. Moçambique era tido como um dos exemplos mais fúlgidos do sucesso das democracias moçambicanas, tão que os próprios autores do Manifesto se distinguiram pelas suas análises, das quais se vislumbrava também um certo otimismo. Alguém chegou a definir esse período como "lua de mel democrática" (SILVA, 2016).

Ngoenha, por exemplo, identificava na interculturalidade, ou seja, na tolerância, e no diálogo o elemento central para ultrapassar divisóes e conflitos internos entre moçambicanos (NGOENHA, 2014), concebendo a historicidade (central mesmo no Manifesto) como reconciliação nacional entre moçambicanos (BUANAÍSSA; PAREDES, 2018). Em suma, Moçambique ainda podia ser considerado um país em devir, uma "comunidade de destino" (MACAMO, 1996), a que todos podiam e deviam participar na definição de uma nova identidade nacional (PAREDES, 2014). 
Em boa verdade, uma larga parte da parca produção filosófica moçambicana das décadas de 1990 e 2000 se debruçou justamente sobre uma tal questão: será que é possível (re)construir um tecido social, humano e até político de convivência comum, depois de 10 anos de luta de libertação e, sobretudo, 16 anos de guerra civil? A resposta tinha sido positiva, embora com diferenciaçóes segundo o pensamento individual de cada um. Mazula (1995), por exemplo, com um importante volume pós-eleitoral relativo às primeiras eleiçóes livres em Moçambique, juntamente com os seus colegas, postulava o caminho para o desenvolvimento e a democracia como o fulcro do renascimento nacional. Nessa altura, Ngoenha refletia primeiro sobre possíveis caminhos que deviam levar Moçambique da independência política a uma plena liberdade (econômica, além de política) (NGOENHA, 1993) e, depois, a postular um novo contrato social, político e cultural entre governantes e governados, em Moçambique (NGOENHA, 2004).

Apesar das críticas, Moçambique parecia encaminhado para um futuro próspero, cujo eixo central era representado da historicidade de um Estado nacional que devia transformar-se, finalmente, em "povo" ou em "nação", e a que todos (salvo os inimigos mais radicais, ou seja, alguns membros da Renamo) podiam contribuir. O "espetro", nesse caso, era representado pelo "tribalismo" ou "regionalismo", o qual, desde os tempos de Mondlane e ainda mais de Machel, tinha sido identificado como o verdadeiro risco pela formação da jovem nação moçambicana (MONDLANE, 1976; MACHEL, 1970). O tribalismo se manifestava em várias formas, entre as quais a educação tradicional e colonial, ambas "obscurantistas", e que impediam o formar-se da nação moçambicana e do homem novo (MACHEL, 1970).

O percurso político, educacional e filosófico que a Frelimo da luta de libertação e dos primeiros anos de independência tinha escolhido apontava para o fortalecimento de uma nação unida e unitária, aceitando, de fato, a principal instituição do capitalismo moderno, o Estado-Nação, recheando-a com receitas socialistas. A reflexão política e filosófica moçambicana nunca meteu em dúvida uma tal opção, fazendo profissão de realismo e tendo como horizonte último o fortalecimento do espaço político-institucional nacional. Depois da viragem democrática dos anos 1990, os termos de referência do debate político mudaram: agora, diante da nova Constituição de 1990, o Estado passa (pelo menos formalmente) a ser moldado pelos princípios clássicos de qualquer outro Estado moderno, tais como o estado de direito, tutela dos direitos humanos, pluralismo político e religioso, paz e por aí 
fora. Um tal caminho sofreu, porém, recuos significativos, até perder as suas caraterísticas essenciais.

O primeiro desses recuos tem de ser identificado com os fatos de 1999 e 2000. Em 1999, as segundas eleiçôes gerais foram amplamente contestadas pela Renamo e provavelmente táo fraudulentas, a ponto de alterar de forma decisiva o resultado final (NUVUNGA, 2013). A seguir, em 2000, iniciouse uma série de assassinatos contra indivíduos que estavam denunciando - a partir de funçóes diferentes - o imbricamento entre elite política da Frelimo e mundo econômico e financeiro local: o jornalista Carlos Cardoso (em 2000) e o economista António Siba-Siba Macuácua (em 2001, que, na qualidade de presidente, estava tentando recuperar os milhóes de créditos que o Banco Austral tinha com políticos e grandes empresários moçambicanos) foram brutalmente eliminados, de forma a silenciar as principais vozes que podiam "incomodar" a nomenklatura mais próxima à Frelimo.

Entretanto, o "espanto" das eleiçốes de 1999 e o clima (usando uma expressão da época) de "deixa-andar" levaram a Frelimo a optar por uma solução radicalmente diferente da governação de Chissano para as eleições presidenciais de 2004. Armando Emílio Guebuza assumiu o poder justamente em 2004, tendo desempenhado as funções de presidente da República até 2014. Em Moçambique, muita coisa mudou.

Além de restringir as liberdades fundamentais (BUSSOTTI, 2015), o presidente Guebuza se engajou num novo conflito contra o inimigo histórico da Renamo. O país pareceu recuar ao clima político anterior à assinatura dos Acordos Gerais de Paz de 1992, em Roma. A situação se tornou ainda mais grave depois das eleiçóes de 2014 (antecedidas pela assinatura de um novo acordo de paz entre Guebuza e o líder da Renamo, Dhlakama), as quais elegeram o primeiro presidente da República proveniente do norte do país, Makonde Filipe Nyusi. Dhlakama náo reconheceu o resultado das eleições, alegando fraudes, iniciando uma campanha primeiro para dividir o país, seguindo a linha do Rio Save, depois exigindo um federalismo ou autonomismo muito avançado, que a Frelimo não tinha a mínima intenção de aceitar. $\mathrm{O}$ jurista franco-moçambicano Jilles Cistac, que apoiava tais teses, foi morto (provavelmente por uma encomenda proveniente de círculos pertencentes ao maior partido do país), em pleno centro de Maputo, em março de 2015, e a ele se seguiram vários outros casos de assassinatos muito suspeitos de terem uma explicação política. A Renamo - corroborada por testemunhas diretas 
(HÁ ESQUADRÓES DA MORTE, 2016) -chegou a falar explicitamente de “esquadrōes da morte" (RENAMO ACUSA FRELIMO, 2019).

Portanto, foi com Guebuza - sobretudo no seu segundo mandato, de 2009 até 2014 - que o tipo de democracia e de convívio entre os moçambicanos se tornou mais claramente conflituoso, difícil e escassamente inclusivo. Pela primeira vez, em Maputo e na vizinha Matola, entre 2008 e 2010, se registaram manifestaçóes de rua antigovernamentais, a que o executivo respondeu, matando pessoas inocentes, com o uso vasto de uma violência policial digna da época colonial (GUERRA HERNANDEZ, 2014). Em paralelo, a corrupção disparou. Guebuza (e a seguir, o seu sucessor, Nyusi) não conseguiu respeitar a sua palavra de ordem da primeira campanha eleitoral, quando evocava a figura (ou o espetro?) de Samora Machel, para "meter na linha" um país já na época altamente corrupto. Fora das superficiais manifestaçôes que Guebuza promoveu, para enaltecer a obra de Machel, nada disso aconteceu, como demonstram as classificaçóes das organizações internacionais, a esse propósito. Transparência Internacional classificou Moçambique, em 2019, como um dos países mais corruptos do mundo, atribuindo-lhe uma pontuação de 26/100, correspondente ao lugar 146 de 180 países, em nível mundial (TRANSPARÊNCIA INTERNACIONAL, 2019), quando, em 2014 ocupava o lugar 137.

O país estava de novo mergulhado numa guerra civil, com a liberdade de expressão fortemente ameaçada e níveis de corrupção político-institucional elevadíssimos, como demonstrado pela descoberta da dívida pública oculta de 2,2 mil milhóes de dólares americanos, de que o Parlamento (e, por conseguinte, o povo moçambicano) nada sabia. Finalmente, em outubro de 2017, um primeiro ataque de tipo supostamente islamita despertou o país, mesmo em relação à sua suposta condição de "ilha feliz", quanto aos conflitos religiosos. Na província nortenha de Cabo Delgado, fronteira com a Tanzânia, até hoje centenas de moçambicanos são mortos em ataques de guerrilha, ultimamente reivindicados pelo Estado Islâmico, onde jazigos enormes de gás estão sendo explorados por multinacionais tais como Exxon e ENI, e onde se encontra um dos maiores jazigos mundiais de rubins (na cidade de Montepuez) (MATSINHE; VALOI, 2019).

Diante dests novo, triste cenário, os intelectuais moçambicanos reagiram de formas diferentes: um grupo muito vasto, incluindo o historiador Egídio Vaz, particularmente ativo nas redes sociais, tomou partido em favor do governo, de maneira acrítica. A eles se devem acrescentar todos os órgãos 
públicos de informação, desde o diário Notícias ao semanário Domingo, desde a Rádio Moçambique até a Televisão de Moçambique. Outros, pelo contrário, acentuaram a sua viés polémica: entre eles, além dos semanários Savana e Canal de Moçambique, o site macuablogs.com, com Fernando Gil, o comentador televisivo e agora deputado da Renamo, Alberto Ferreira (Domus Oikos, nas redes sociais), assim como Severino Ngoenha e, em parte, Castiano.

Foi diante de um tal pano de fundo que o Manifesto teve a sua origem: já não era possível manter o silêncio perante processos corruptivos de tão tamanha dimensão e difusão, de duas guerras que continuam a assolar o país (no Centro, contra os rebeldes da Renamo e, no Norte, contra os supostos radicais islâmicos), da irresponsabilidade de uma inteira classe dirigente para com o seu povo. As bases da convivência civil e humana que tinham sido codificadas com a Constituição de 1990 e com a sua alteração de 2004 já estavam sofrendo ruturas consideráveis. Daqui, a ideia de elaborar um documento com um título chamativo, justamente o Manifesto, que os dois autores quiseram lançar à atençáo da nação moçambicana, em plena campanha eleitoral. Porém, o âmbito privilegiado desse Manifesto é de tipo ético, uma vez que parte do pressuposto da indignaçáo moral proveniente da irresponsabilidade dos políticos locais, apelando para que todos os moçambicanos de boa vontade voltem a se interessar da sua comunidade nacional, saindo de uma conflitualidade que está afetando o futuro de Moçambique.

\section{A DiMENSÁo HISTÓRICA DO MANIFESTO}

O Manifesto se enquadra, como visto também, no ponto anterior, no seio de uma historicidade que os dois autores nunca têm negligenciado, ao longo da sua produção intelectual. Sobretudo Ngoenha tem feito disso um dos marcos centrais para definir o campo de atuaçáo do seu pensamento engajado. Seu primeiro livro, escrito em 1991, abordou justamente a questão filosófica da consciência histórica moçambicana, na tentativa de refletir sobre a edificação de uma nação nova, dentro dos limites possíveis da dimensão política internacional e a partir das experiências marcantes do passado (NGOENHA, 1991).

No Manifesto, uma tal dimensão histórica é recuperada em dois sentidos: primeiro, considerando o próprio percurso coletivo de Moçambique, desde a altura pré-colonial até hoje; e, segundo, procurando inserir a experiência moçambicana na mais larga perspetiva da filosofia africana "libertadora". 
Os autores identificam quatro momentos centrais da dimensão histórica de Moçambique: o primeiro é o das "cosmogonias pré-moçambicanas" (NGOENHA; CASTIANO, 2019, p. 18), as quais antecedem, portanto, a ocupação colonial. É interessante notar, aqui, que - diferentemente do que acontece com uma boa parte do pensamento africano contemporâneo, que visa a resgatar culturas e práticas pré-coloniais (FALOLA, 2000; BUSSOTTI; NHAUELEQUE, 2018) - no Manifesto, o momento pré-colonial não é valorizado. Com efeito, diante do objetivo da formação de uma nação moderna, os autores defendem que as cosmogonias originárias foram incapazes de formular o conceito de Moçambique e de nação, pelo que foi necessário esperar até a manifestação da dialética que se abriu com o colonialismo, a fim de ver um movimento minimamente consciente e unitário sob o ponto de vista das intençóes políticas.

A segunda fase histórica analisada no Manifesto corresponde à experiência colonial. O marco típico do colonialismo foi - segundo os autores - a definição de uma territorialidade nacional dada. Aqui, a filosofia moçambicana se cruza e se sobrepóe a alguns dos princípios fundadores da filosofia africana tout court. Com efeito, excluindo algumas correntes modernas, tais como o afrocentrismo de Asante, inspirado por Anta Diop (ANTA DIOP, 1955; ASANTE, 2003), que encontra no Egito antigo as raízes da filosofia africana, uma larga parte do pensamento atual concorda em identificar o primeiro esforço coletivo de sistematização de um pensamento africano independente na oposição à escravatura e ao colonialismo.

Kanu Anthony, por exemplo, enfatiza essa origem "por oposição", a partir das representaçóes que do negro eram feitas por parte dos classificadores das raças humanas, tais como Gobineau, da anulação humana consequência do tráfico esclavagista, do colonialismo e do neocolonialismo (ANTHONY, 2014). Certos pensadores afroamericanos, a exemplo de Garvey e Du Bois, já nos finais do século XIX iam em busca da liberdade da opressão esclavagista ou pós-esclavagista; em paralelo, segundo Ngoenha, no continente africano, os primeiros filósofos modernos foram alguns entre os principais líderes dos movimentos de libertação, tais como Azikiwè, Nkrumah, Mondlane, Cabral, Nyerere (NGONHA, 2004). Em suma, trata-se de um paradigma libertário que, primeiro na diáspora, depois no continente africano, assume os contornos de uma filosofia madura e independente das influências ocidentais.

O colonialismo e a escravatura moldaram esse primeiro período da filosofia africana moderna, entretanto, no Manifesto, são apresentados dois 
aspetos relevantes de um tal pensamento: por um lado, o colonialismo é negador das identidades locais, mas, por outro, foi justamente o colonialismo que despertou a necessidade de um pensamento unitário e nacionalista, num país como Moçambique, o qual, até 1975, esteve ocupado por Portugal. O colonialismo deu, portanto, as balizas onde direcionar o jogo, ou seja, os limites territoriais do atual Moçambique; todavia, defendem Ngoenha e Castiano, é preciso ir além disso, pois o sentido ontológico da cidadania moçambicana ultrapassa a significação negativa típica do colonialismo (NGOENHA; CASTIANO, 2019).

Foi essa capacidade de "ir além", de construir uma comunidade possível e livre que fomentou a luta de libertação. Os dois autores cumprem uma profissão de realismo, ao afirmar, inspirando-se em Eduardo Mondlane: "As fronteiras coloniais são pertinentes [...] enquanto assunção geopolítica consciente e pragmática para a unidade interna, para o reconhecimento internacional, mas sobretudo espaço onde se nos é dado a exercer nossa cidadania.” (NGOENHA; CASTIANO, 2019, p. 34). Não que uma tal dimensão constitua o ideal institucional, para os dois autores. Com efeito, eles resignadamente defendem que as alternativas que tinham sido propostas por vários pensadores, todas eles embasadas em perspetivas pan-africanistas (de Nkrumah a Mamadou Dia até Anta Diop) foram descartadas, preferindo uma quarta via, a de intangibilidade das fronteiras coloniais e da não ingerência, de sorte a assinalar a "[...] vitória, quer dos neocolonialistas [...], quer dos homens pequenos com ambiçóes individuais pelo poder." (NGOENHA; CASTIANO, 2019, p. 32).

Dentro da moldura do Estado nacional colonial que África herdou, que tipo de consciência coletiva foi edificada, por parte dos moçambicanos?

A resposta que Ngoenha e Castiano fornecem constitui o fulcro do raciocínio do Manifesto: numa primeira fase, ao longo da experiência socialista (a "primeira via"), a nação que foi construída atendeu a um pressuposto essencial, na altura. Tal pressuposto coincidia com a implementação de um modelo baseado na justiça social, a que se contrapôs uma "segunda via" (a do liberalismo, a partir dos anos 1990), a qual privilegiava as liberdades individuais, deixando por detrás a "questão social". Em boa verdade, a análise realizada no Manifesto a propósito das duas primeiras vias merece um maior aprofundamento, uma vez que elas representam as últimas duas fases histórico-políticas consideradas no livro e, para superar as quais, foi postulada uma "terceira via". 
Quanto à primeira via, os autores argumentam que ela implementou uma democracia de massa "por força", imposta por uma minoria (NGOENHA; CASTIANO, 2019, p. 21). O sistema que foi montado tinha fortes continuidades com o de tipo colonial, com o acréscimo da imitação do modelo socialista; entretanto, considerada a fase histórica em que Moçambique se tornou independente, "não havia alternativa" (NGOENHA \& CASTIANO, 2019, p. 47). Porém, apesar dessa ressalva, os autores apontam uma contradição de fundo que está na base de uma tal opção: o socialismo adotado em Moçambique foi muito mais "científico" do que "afrocomunitário", segundo quanto Nyerere na Tanzânia, com a experiência da Ujamaa, e Senghor, no Senegal, tinham feito.

Contudo, num país extremamente pobre e que acabava de sair dum colonialismo também pobre, como o de tipo português, a sociedade não estava estruturada para receber um socialismo de inspiração marxista: assim como faltavam os capitalistas, da mesma forma não havia uma classe operária digna desse nome. Sem possuir os elementos fulcrais para implementar um programa socialista moderno, a tentativa feita por Samora Machel faliu. E, nesse falhanço, o que iniciou a ser carente foi justamente a "vigilância sobre nós próprios" (NGOENHA; CASTIANO, 2019, p. 51). Isso levou a abusos, arbitrariedades, violaçóes desnecessárias dos direitos mais fundamentais do homem, os quais aceleraram a queda do regime e a transição para a "segunda via”. Dentro da experiência socialista, porém, a busca de justiça social mediante uma difusa solidariedade foi constante e moldou a primeira identidade coletiva moçambicana.

A guerra civil que assolou o país durante 16 anos é lida pelos autores do Manifesto como um evento que serviu, acima de tudo, a interesses alheios, externos à agenda política moçambicana. Sem gastar muito tempo na análise do conflito entre Frelimo e Renamo, Ngoenha e Castiano resolvem tal questão de modo, por assim dizer "ecuménico", ao afirmar que ela foi "[...] uma derrota estrondosa para os moçambicanos." (NGONHA; CASTIANO, 2019, p. 54). Uma leitura simplista, esta, que porém é funcional a um dos eixos fundamentais da proposta da "terceira via", da qual se dirá melhor mais a frente, mas que - em jeito de antecipação - é possível aqui identificar com a necessidade de uma reconciliaçáo nacional generalizada.

A guerra civil foi decisiva para que o país transitasse da primeira à segunda via, a qual representa a quarta e última etapa histórica considerada pelos autores. Não é por acaso que ela se inicia com os Acordos Gerais de Paz de 
Roma, em 1992, sendo antecedida pela aprovação, por parte de um parlamento ainda monopartidário, da nova Constituição liberal, em 1990. Assim como a primeira via tinha fortes limitaçôes, em termos de liberdade individual, mas méritos quanto à formação de uma identidade nacional embasada na justiça social, a segunda via também assinala limitaçôes consideráveis. Acima de tudo, a segunda via liberal garantiu, de fato, aquelas liberdades individuais e fundamentais que a primeira tinha negado, mas negligenciando por completo mecanismos compensatórios de tipo solidarístico para com os mais carenciados.

Aqui, as críticas se fazem ainda mais ásperas, por parte dos dois autores. O ultraliberalismo (ou neoliberalismo, segundo Castiano) teria assumido manifestaçóes extremas, vindas, mais uma vez, de fora do país, contudo, com a contribuição de "[...] indivíduos cooptados, com a máscara da democracia.” (NGOENHA; CASTIANO, 2019, p. 54). A riqueza, a dólarcracia, se tornou o único deus da segunda via, com abundante contorno de corrupçáo, malabarismo, perda de qualquer sentido da comunidade, interesses particulares prevalecendo nos interesses públicos. A falta de um ideal comum à nação moçambicana é que representa, segundo o Manifesto, a maior limitação da segunda via. Daqui, a perspetiva enraizada numa análise ética, antes do que política, para preparar a terceira via.

A terceira via - que resultaria da junção entre busca da justiça social da primeira e da liberdade da segunda - tem de assentar, acima de tudo, em indivíduos "íntegros e competentes" a guiar o país (NGOENHA; CASTIANO, 2019, p. 56), separando os poderes e, em termos políticoinstitucionais, fortalecendo o estado de direito. Segundo os autores, apenas um país com instituições fortes e capazes é que poderá ultrapassar a crise de valores e de identidade atual, projetando-se para um futuro mais róseo.

Porém, a terceira via tem uma importante componente de tipo histórico também, coerentemente com toda a análise feita acima. A história de Moçambique é uma história de conflitos, incompreensôes, abusos e vinganças, a qual dividiu os moçambicanos, ao invés de uni-los. Daqui, a necessidade de uma reconciliação inclusiva e não jurídica, ou seja, sem pensar em tribunais que façam julgamentos a posterior, segundo o modelo sul-africano implementado por Nelson Mandela, e que dariam azo a mais conflitos e ódio. A história nacional e o seu repensamento deveria, portanto, recoser tecidos sociais e humanos rompidos, os quais influenciaram negativamente a construção da moçambicanidade. Uma moçambicanidade que, como vimos 
na primeira parte deste texto, constituiu uma "comunidade de destino", um anseio coletivo durante pelo menos duas décadas, mas que depois naufragou diante das degeneraçóes da "segunda via".

A referência histórica e política da terceira via é Eduardo Mondlane, que conseguiu juntar, no seu pensamento e na sua obra, na qualidade de presidente da Frelimo, até a sua morte, em 1969, o ideal de autêntico democrático com os da justiça social, que depois sofreram uma bifurcação na experiência da primeira e da segunda via. Hoje, com a terceira via, os dois autores propóem reconetar os ideais de Mondlane com a historicidade do tempo presente, envolvendo os mais jovens na determinação de um novo pacto social.

A terceira via, como bem explicam os autores, não é, pois, uma receita política fechada, nem uma utopia, mas uma proposta fatual e concreta para abrir uma discussão, cujos termos de referência podem ser assim resumidos: quais as bases para um novo pacto social entre moçambicanos? Quais as vias para uma reconciliação nacional? Como sair da dependência econômica que limita a liberdade a uma esfera meramente política, negligenciando todas as outras? Finalmente, como remobilizar os moçambicanos mais conscientes, para construir uma nova identidade nacional, juntando liberdade, solidariedade e justiça social, de sorte, assim, a sair da dólar-cracia imperante?

Em suma, o Manifesto representa muito mais um convite à reflexão e à ação do que uma receita predeterminada, com algumas balizas que os autores identificam e que, aqui, se tentou resumir.

\section{UM BALANÇO: O LEGADO DO MANIFESTO E ALGUMAS DE SUAS INQUIETAÇÓES}

O Manifesto, pela sua natureza, é um pequeno tratado ético-político que visa a restabelecer laços solidários entre os moçambicanos, depois de anos de conflitos, guerras e tensóes, com condimento de elevadíssimos índices de corrupção. O seu grande mérito é ter estimulado um debate sobre as questóes de fundo, de tipo ontológico, da convivência nacional, num momento de gravíssima crise de valores e de referências mesmo de tipo político, como as últimas eleiçóes gerais de 15 de outubro de 2019 têm amplamente demonstrado. $\mathrm{E}$, ao mesmo tempo, ter oferecido uma plataforma aberta e inclusiva, para que todos possam participar dessa difícil tentativa de reconciliação e reconstrução nacionais. O seu posicionamento é razoavelmente realístico, uma vez que 
a componente utópica é reduzida ao mínimo necessário, pois o objetivo é contribuir a melhorar as condições do país hic et nunc.

Entretanto, existem ambiguidades, contradiçóes e aspetos que o texto omite, os quais também poderão ser objeto de discussão, no debate sobre a refundação de Moçambique:

1. O plano da análise histórica: tratando-se de um Manifesto, ou seja, de um tratado breve com intenção divulgativa, forçosamente a análise feita não pôde ter aquela profundidade que seria necessária para textos mais propriamente científicos. Todavia, existem elementos que podem ser objeto de crítica e de aprofundamento, sobretudo quanto àquela "historicidade" que representa o pano de fundo de todo o livro. Acima de tudo, a consideração das sociedades pré-coloniais: é verdade que elas são lidas na ótica do interesse prevalecente dos dois autores, ou seja, a da formação de uma moderna nação e, por isso, desvalorizadas. Entretanto, estudos que já datam dos anos 1990 retificam uma tal imagem, enfatizando que as chefaturas pré-coloniais contribuíram a dar um primeiro sentido identitário e até uma certa coesão política aos povos, quer ao norte, quer ao sul do Zambeze (LUNDIN, 1995; LOURENÇO, 2012). Além disso, ambos os autores têm defendido, em várias das suas obras, os princípios da filosofia Ubuntu: Ngoenha falando da importância da partilha do munios (NGOENHA, 2013), Castiano do ubuntuísmo como código de respeito que afunda as suas raízes na cultura africana pré-colonial, mas que tem a capacidade de dar respostas também às questóes éticas e de convivência humana mais modernas (CASTIANO, 2010; SOARES; PEREIRA, 2016). Provavelmente, uma reflexão mais atenta sobre as capacidades de construção identitária por parte das sociedades pré-coloniais moçambicanas, pelo menos na perspetiva cultural, se não política, teria tornado o texto mais coerente. A segunda "historicidade" a ser compulsada tem a ver com a análise que os autores fazem da primeira e da segunda via. Uma análise que, no primeiro caso, carece de uma releitura provavelmente mais corajosa da experiência da Frelimo socialista. No livro, é verdade, fala-se abertamente das limitaçóes de um tal género de governação, enfatizando-se a falta de democracia e de qualquer tipo de espaço público de discussão; porém, os dois 
autores evitam usar tons mais duros - que hoje muita parte da crítica histórica já tem usado com provas sólidas (NCOMO, 2003; THOMAZ, 2008) -, denunciando as terríveis violações dos direitos humanos perpetradas contra civis inocentes, além de contra os inimigos políticos, assim como a arbitrariedade jurídica que o regime de Samora Machel praticou, nos julgamentos populares. Vários observadores têm apelado para que se constituísse, em Moçambique, uma comissão nacional de verdade e reconciliação, a qual pudesse esclarecer as atrocidades cometidas ao longo da guerra civil e por parte do governo socialista da Frelimo, saindo de uma visão oficial dessa parte da história do país que já denunciou todas as suas parcialidades e limitaçóes (SOUSA SANTOS, 2004). No entanto, os autores do Manifesto assumem um posicionamento menos duro, imaginando que a questão principal tem de ser a reconciliaçáo e o perdão, que não passa necessariamente pelo apuramento de uma verdade que inclusivamente seria difícil de estabelecer e muito dolorosa. Finalmente, sobre a segunda via, ou seja, o período liberal, Ngoenha e Castiano expressam palavras extremamente contundentes em relação aos políticos moçambicanos, corruptos e em completa debandada, sob o ponto de vista ético e político. Porém, eles negligenciam uma análise sobre a verdadeira natureza da democracia moçambicana, ou suposta tal: uma democracia dominada por um partido, a Frelimo, que ganhou talvez todas as eleições (e certamente as de 1999, 2014 e as últimas de 2019) mediante fraudes hoje comprovadas e tornadas públicas, ignorando por completo os mais elementares mecanismos de lealdade, não apenas, e náo tanto para com os seus adversários políticos, quanto com os próprios eleitores. $\mathrm{O}$ mecanismo de controlo total do poder e dos poderes que a Frelimo manteve, mesmo depois da abertura liberal dos anos 1990, fez das instituiçôes de Moçambique, a partir dos processos eleitorais e dos seus órgãos teoricamente imparciais, um mero simulacro de democracia, que nenhuma forma de simples voluntarismo poderá desmontar. Dizer, por conseguinte, que a segunda via garantiu as liberdades fundamentais é um mero exercício teórico, que não corresponde à verdade diária que os moçambicanos vivenciam até hoje. Em suma, se é evidente a escolha dos autores em enfatizar mais a crise ética de Moçambique do que a política, dificilmente uma 
refundação da primeira será possível, sem incidir profundamente e radicalmente na segunda.

2. O plano da análise política. O principal elemento políticoinstitucional a ser considerado é a emergência do Estado-Nação africano (e moçambicano) das cinzas do colonialismo. A esse propósito, os autores têm-se posicionado de maneira clara, fazendo uma profissão de realismo em considerar como único espaço possível (embora não preferido) de atuação o território definido pelo colonialismo, e que os Estados africanos (e a União Africana) assumiram como definitivo. Todavia, seria possível, aqui, lançar um desafio, que está fora dos interesses peculiares assentes na reflexão do Manifesto, mas que náo deixa de ter uma sua constante atualidade: não convinha - numa perspetiva estratégica e de longo prazo - iniciar a refletir sobre a opção que foi descartada nos anos 1960, e que enaltecia não tanto o Estado nacional africano quanto os Estados Unidos da África, ou, pelo menos, a valorização de mecanismos de integração regional, tais como a SADC, a CEDEAO etc.? Não se trata de uma proposta utópica (que está fora do âmbito do Manifesto), contudo, de uma reflexão coerente com quanto os dois autores defendem: a necessidade de estabelecer uma liberdade econômica, além de uma política, para Moçambique. Fica complicado imaginar que uma tal autonomia possa ser alcançada continuando o país a negociar sozinho, sobre os grandes investimentos, com gigantes como os EUA ou a China, ou continuar a lidar sem a ajuda dos países vizinhos com situaçóes gravíssimas, tais como a guerra presente em Cabo Delgado, desde outubro de 2017, contra supostos radicais islâmicos, em que o exército nacional já tem demonstrado a sua incapacidade de contenção e de contra-ataque. Em suma, começar a imaginar um fortalecimento das instituiçóes suprarregionais, com uma parcial cedência do poder a nível nacional dos Estados da SADC, poderia constituir um momento significativo de superação das dificuldades com que Moçambique se está deparando, nos últimos anos. A outra questão que o Manifesto toca apenas, mas que seria de tamanho interesse debater publicamente, assenta na divisão dos poderes. Partindo da consideração de que o Manifesto identifica no estado de direito o elemento central para reformar as instituiçôes moçambicanas, faria sentido denunciar a 
concentração dos poderes nas mãos do presidente da República, que resume em si o poder executivo, legislativo e judiciário, como a maior limitação constitucional sem ultrapassar a qual qualquer outro tipo de reformas acabaria sendo pouco produtivo, assim como tem acontecido com a recente apreciação do dito pacote da descentralização, aprovado em 2019, cujos resultados têm sido modestos.

\section{Consideraçoes Finais}

A sintética análise do Manifesto tem demonstrado a necessidade de uma reflexão livre e profunda sobre as razóes da convivência comum em Moçambique, de que hoje se tem perdido boa parte do sentido último. Ngoenha e Castiano, portanto, têm movido o primeiro passo para que os moçambicanos voltem a debater e a interrogar-se sobre aquela "comunidade de destino" que parece ter perdido o seu rumo, disperdendo-se e perdendo-se no meio de egoísmos, corrupçáo, conflitos antigos e novos. Como foi possível observar, no último ponto, nem todo o raciocínio dos autores é plenamente linear e coerente, assim como nem toda a sua análise é profunda e ousada.

Entretanto, a leitura da "historicidade" moçambicana, a qual representa o cerne do Manifesto, tenciona levar a uma reconciliação nacional, sem a qual os ódios e as vinganças irão continuar a dominar um país atualmente mergulhado em duas guerras civis, de que fica difícil vislumbrar o fim. Talvez seja por isso que o Manifesto apresenta algumas lacunas e omissóes: porque ele procura edificar um novo Moçambique, no qual o bem supremo, a paz, nunca possa ser ameaçado, e em que quem quiser contribuir ao debate de refundação possa fazê-lo livremente e sem medo. Dois objetivos que, apesar do posicionamento contrário dos dois autores, parecem neste momento carregados de uma boa dose de utopia - que é, provavelmente, o que está faltando ao pensamento engajado moçambicano contemporâneo. 
BUSSOTTI, L. A manifesto for Mozambique: the third way of Ngoenha and Castiano. Trans/Form/Açáo, Marília, v. 45, p. 67-88, 2022. Edição Especial.

\begin{abstract}
Plunged into a great crisis of values, with a political class highly corrupted and unable to offer credible perspectives for its future, Mozambique saw the philosophers Ngoenha and Castiano tried to open an innovative debate, through the proposal of an ethical-political Manifesto. The Manifesto proposes a "third way" alternative to the first one (the socialist, without freedoms but with social justice), as well as to the second (the liberal, with individual freedoms formally guaranteed, but without solidarity, nor social justice), with the aim to re-build the sense of a collective national identity shaken up by the loss of a common project for the young Mozambican nation. The current article seeks to give an interpretation to the Manifesto, besides to compel its meaning, emphasizing its merits as well as pointing out its limitations, in a permanent dialogue with the Mozambican and African philosophical tradition at all. As a conclusion, the Manifesto represents one of the rare contributions, based on "historicity", directed to think again of Mozambique, in its ethical, political and identity aspects, in an era of generalized crisis of this country.
\end{abstract}

Key-words: Mozambican Philosophy. Ethics. Crisis of Values. Historicity

\title{
REFERÊNCIAS
}

ANTA DIOP, C. Nations nègres et culture. Paris: Presence Africaine, 1995.

ANTHONY, K. The Meaning and Nature of African Philosophy in a Globalising World. International Journal of Humanities Social Sciences and Education, v. 1, n. 7, p. 8694, 2014. Disponível em: https://www.arcjournals.org/pdfs/ijhsse/v1-i7/10.pdf. Acesso em: 15 nov. 2019.

ASANTE, M. K. Afrocentricity. Chicago (Illinois): African American Images, 2003.

BUANAÍSSA, E. F.; PAREDES, M. de M. Severino Ngoenha: política e liberdade no Moçambique contemporâneo. Opiniáo Filosófica, v. 9, n. 1, p. 5-26, 2018. Disponível em: periódico.abavaresco.com.br. Acesso em: 12 dez. 2019.

BUSSOTTI, L. Media Freedom and the “Transition” Era in Mozambique:1990-2000. In: BUSSOTTI, L.; BARROS, M.; GRATZ, T. (ed.). Media Freedom and Right to Information in Africa. Lisbon: ISCTE-IUL, 2015. p. 45-71.

BUSSOTTI, L.; NHAUELEQUE, L. A. A Invenção de uma tradição: as fontes históricas no debate entre Afrocentristas e seus críticos. História - Revista da UNESP. São Paulo, v. 37, p. 1-28, 2018. Disponível em: DOI: http://dx.doi.org/10.1590/19804369e2018005. Acesso em: 12 dez. 2019.

CASTIANO, J. P. Referênciais da Filosofia Africana: em busca da intersubjectivação. Maputo: Ndjira, 2010. 
CASTIANO, J. P. A “liberdade” do neoliberalismo: leituras críticas. Maputo: Educar, 2018.

FALOLA, T. (ed.). Africa, Volume 1: African History Before 1885. Durham, NC: Carolina Academic Press, 2018.

GUERRA HERNANDES, H. Modernidade seletiva e estado predador. Antropologia e políticas globais, v. 41, p. 201-232, 2014. Disponível em: https://journals.openedition. org/horizontes/588?lang=fr. Acesso em: 12 out. 2019.

HÁ esquadróes da morte para abater opositores, revela agente da Polícia da República de Moçambique. @Verdade, 11 mar. 2016. Disponível em: http://www.verdade.co.mz/ tema-de-fundo/35-themadefundo/57164-ha-esquadroes-de-morte-para-abater-opositoresrevela-agente-da-policia-da-republica-de-mocambique. Acesso em: 12 out. 2019.

LOURENÇO, V. Estado(s) e Autoridades Tradicionais em Moçambique: Análise de um Processo de Transformação Política. Lisboa: Centro de Estudos Africanos. Occasional Paper n. 14, 2012. Disponível em: https://repositorio.iscte-iul.pt/ bitstream/10071/3826/1/CEA_OP_VITOR_MO\%C3\%87AMBIQUE_14.pdf. Acesso em: 12 out. 2019.

LUNDIN, I. A pesquisa piloto sobre a autoridade/poder tradicional em Moçambique: um somatório comentado e analisado. In: LUNDIN, I.; MACHAVA, F. (org.). Poder e Autoridade Tradicional, V. I. Maputo: MAE/NDA, 1995.

MACAMO, E. A nação moçambicana como comunidade de destino. Lusotopie, p. 355364, 1996.

MACHEL, S. Educar o homem para vencer a guerra - criar uma sociedade nova e desenvolver a pátria. Maputo: FRELIMO, 1970.

MATSINHE, D. M.; VALOI, E. 2019. The genesis of insurgency in northern

Mozambique. Pretoria: Institute for Security Studies. Disponível em: https://issafrica. s3.amazonaws.com/site/uploads/sar-27.pdf. Acesso em: 12 out. 2019.

MAZULA, B. (org.). Moçambique: eleições, democracia e desenvolvimento. Maputo, 1995.

MONDLANE, E. Lutar por Moçambique. Lisboa: Sá da Costa, 1976.

NCOMO, B.L. Uria Simango: Um Homem, Uma Causa. Maputo: Novafrica, 2003.

NGOENHA, S. Por uma dimensáo moçambicana da consciência histórica. Porto: Salesianas, 1991.

NGOENHA, S. Filosofia africana: das independências às liberdades. Maputo: Imprensa Universitária, 1993.

NGOENHA, S. Os tempos da filosofia. Maputo: Imprensa Universitária, 2004.

NGOENHA, S. Samora Machel. Ícone da 1a República. Maputo: Ndjira, 2009. 
NGOENHA, S. Intercultura, alternativa à governação biopolítica? Maputo: Publifix, 2014.

NGOENHA, S.; CASTIANO, J.P. Pensamento engajado. Maputo: Educar, 2011.

NGOENHA, S.; CASTIANO, J.P. Manifesto por uma terceira via. Maputo: Real Design, 2019.

NUVUNGA, A. Políticas de eleiçôes em Moçambique: As experiências de Angoche e Nicoadala. In: DE BRITO, L.; CASTEL-BRANCO, C. N.; CHICHAVA, S.; FRANCISCO, A. (org.). Desafios para Moçambique 2013. Maputo: IESE, 2013. p. 39-54.

PAREDES, M. de M. A construção da identidade nacional moçambicana pósindependência: sua complexidade e alguns problemas de pesquisa. Anos 90, v. 21, n. 40, p. 131-163, 2014. Disponível em: seer.ufrgs.br/anos90/article/view/46176. Acesso em: 12 out. 2019.

RENAMO acusa FRELIMO de reativar "esquadróes da morte". Deutsche Welle, 12 nov. 2019. Disponível em: https://www.dw.com/pt-002/renamo-acusa-frelimo-de-reativaresquadr\%C3\%B5es-da-morte/a-51211525. Acesso em: 12 nov. 2019.

SILVA, C. R. As eleições e a democracia moçambicana. Janus 2015-2016, p. 34-35, 2015. Disponível em: http://janusonline.pt/images/anuario2015/1.13_CarolinaSilva_ DemocraciaMocambique.pdf. Acesso em: 12 nov. 2019.

SOARES, J. G.; PEREIRA, M. A. S. Ubuntuísmo: A Solidariedade Africana. Revista Litterarius, v. 15, n. 1, 2016. Disponível em: http://br60.teste.website/-fapas413/index. php/litterarius/article/viewFile/804/682. Acesso em: 12 nov. 2019.

SOUSA SANTOS, B. de. Boaventura quer verdade. Correio da Manhá, 4 set. 2004. Disponível em: https:/www.google.com/amp/s/www.cmjornal.pt/cm-ao-minuto/amp/ boaventura-quer-verdade. Acesso em: 12 nov. 2019.

THOMAZ, O. "Escravos sem dono": a experiência social dos campos de trabalho em Moçambique no período socialista. Revista de Antropologia, v. 51, 2008. Disponível em: DOI: https://doi.org/10.1590/S0034-77012008000100007. Acesso em: 12 out. 2019.

TRANSPARÊNCIA INTERNACIONAL. Índice de Percepçáo da Corrupçáo 2019. Disponível em: https://ipc.transparenciainternacional.org.br/?gclid=EAIaIQobChMImru Pl4Gq5wIVk4aRCh0HNwBEEAAYASAAEgLfp_D_BwE. Acesso em: 25 fev. 2019.

Recebido: 06/3/2020

Aceito: $11 / 7 / 2020$ 